\title{
PEMODELAN TRANSFER PANAS DAN MASSA PADA PROSES PENGERINGAN BIJI-BIJIAN SISTEM RAK BESERTA SOLUSI NUMERIKNYA
}

\author{
Sigit Ristanto ${ }^{1}$, Choirul Huda ${ }^{2}$ \\ ${ }^{1,2}$ Pendidikan Fisika Universitas PGRI Semarang, Jln. Sidodadi timur no. 24 Semarang Jawa Tengah \\ e-mile: sigit.ristanto@gmail.com
}

Diterima: 23 September 2016. Disetujui: 12 Oktober 2016. Dipublikasikan: Oktober 2016

\begin{abstract}
Modeling of heat and mass transfer determine the form of mathematical equations obtained. The aim of this study was to obtain heat and mass transfer equation based on modeling has been prepared and finished using numerical methods. The study starts from determining assumptions, construction of models, make up the mathematical equation of heat and mass transfer, determine the type of numerical methods used, complete the heat and mass transfer equations using numerical methods that have been chosen. Grains as the dried thing modeled as porous bodies. The results shows that the numerical solutions have been successfully made with a series of requirements that must be met to stability.
\end{abstract}

\begin{abstract}
Abstrak:Pemodelan transfer panas dan massa menentukan bentuk persamaan matematis yang diperoleh. Tujuan penelitian ini adalah memperoleh persamaan transfer panas dan massa berdasarkan pemodelan yang telah disusun lalu menyelesaikannya menggunakan metode numerik.Tahapan penelitian dimulai dari menentukan asumsi-asumsi, menyusun model, menyusun persamaan matematis transfer panas dan massa, menentukan jenis metode numerik yang digunakan, menyelesaikan persamaan transfer panas dan massa menggunakan metode numerik yang telah dipilih.Biji-bijian sebagai benda yang dikeringkan dimodelkan sebagai benda porous. hasil penelitian menunjukkan bahwa solusi numerik telah berhasil disusun beserta serangkaian syarat kesetabilan yang harus dipenuhi.
\end{abstract}

(C) 2016 Pendidikan Fisika, FTK IAIN Raden Intan Lampung

Kata kunci: biji-bijian, metode numerik, ruang pengering tipe rak, transfer panas dan massa.

\section{PENDAHULUAN}

Pengeringan merupakan salah satu tahapan penting dalam perlakuan paska panen. Biji-bijian seperti kedelai, kopi, jagung, beras, dan lain sebagainya membutuhkan proses pengeringan agar terhindar dari jamur.

Penelitian

tentang proses pengeringan telah banyak dilakukan. Rahayuningtyas, A. dan Afifah, N. (2016) telah melakukan penelitian tentang rancang bangun, uji performa dan analisa biaya pengeringan irisan singkong menggunakan pengering infra merah. Jenis pengeringan yang digunakan adalah tipe rak. Hasil penelitiannya menunjukkan untuk mengeringkan $36 \mathrm{~kg}$ irisan singkong dengan kadar air awal 60,23 \% turun hingga 7,56 \% membutuhkan waktu 5 jam dengan kebutuhan energi 2,5 kg LPG.

Putra, G.M.D.,dkk (2016) telah meneliti tentang kajian pindah panas tungku biomassa dan heat exchanger pada alat pengering hybrid berbahan bakar limbah biomass. Agustina, R.,dkk (2016) telah meneliti tentang karakteristik pengeringan biji kopi dengan pengering tipe bak dengan sumber panas tungku sekam kopi dan kolektor surya. Kadar air kopi yang semula $48,7 \%$ telah berhasil diturunkan menjadi $11,66 \%$ di bawah standar SNI yaitu $12,5 \%$.

Pada proses pengeringan melibatkan peristiwa perpindahan panas dan perpindahan massa. Perpindahan panas terjadi dari udara panas menuju bahan 
yang dikeringkan sedangkan perpindahan massa terjadi dari bahan yang dikeringkan menuju udara untuk pengeringan.

Jika persamaan transfer panas dan massa diketahui maka lama waktu pengeringan dapat dihitung. Disinilah letak urgensi pemodelan matetatis. Pemodelan yang baik mampu memprediksi lama waktu pengeringan dengan presisi. Pemodelan juga memungkinkan para ilmuwan mengetahui kinerja pengering tanpa harus membuatnya terlebih dahulu sehingga dapat menghemat biaya.

Penelitian tentang solusi numerik persamaan transfer panas dan massa untuk proses pengeringan telah banyak dilakukan. Silva (2016) telah meneliti tentang pendekatan numerik untuk menjelaskan proses pengeringan secara kontinyu maupun berselang termasuk periode pencampurannya. Romdhana,dkk (2016) telah meneliti tentang teknik model reduksi untuk simulasi yang lebih cepat pada proses pengeringan bahan makanan berbentuk bola pejal. Hasil penelitiannya menunjukkan bahwa metode tersebut mampu mensimulasikan lebih cepat dengan hasil yang tidak jauh berbeda dengan metode konvensional. Zdanski dan Silva (2016) telah melakukan penelitian tentang simulasi numerik aliran turbulen tak termampatkan pada campuran uap air dan udara untuk proses pengeringan. Hasil penelitiannya menunjukkan bahwa laju aliran dan ekspansi fluida sangat berpengaruh terhadap proses pengeringan. Zheng, dkk (2016) telah meneliti tentang prediksi terbalik pada difusivitas campuran menggunakan algoritma genetik. Hasil penelitiannya menunjukkan bahwa difusivitas efektif campuran berada pada rentang $1.120 \times 10^{-9}$ hingga $1.277 \times$ $10^{-8} \mathrm{~m}^{2} / \mathrm{s}$.

Pada penelitian ini akan dilakukan pemodelan transfer panas dan massa pada proses pengeringan biji-bijian tipe rak. Tujuan dari penelitian ini adalah memperoleh persamaan transfer panas dan transfer massa dan menyelesaikannya menggunakan metode numerik. Pemodelan dan batasan masalah yang digunakan dalam penelitian ini merupakan pembeda dari penelitian-penelitian yang telah ada.

\section{METODE PENELITIAN}

Penelitian ini dimulai dari menentukan jenis bahan yang dikeringkan. Setelah itu, menetapkan batasan masalah untuk mengidentifikasi variabel-variabel yang terlibat dalam proses perhitungan. Setelah asumsi dan batasan masalah dibuat langkah berikutnya adalah menerapkan hukum kekekalan energi dan massa untuk memperoleh persamaan transfer panas dan massa. Selanjutnya, persamaan tersebut diselesaikan secara numeris dengan menerapkan syarat batas dan syarat awal yang telah ditetapkan. Metode numerik yang digunakan adalah metode beda hingga dengan penyelesaian secara eksplisit. Terakhir adalah melakukan pengujian syarat kesetabilan.

\section{HASIL DAN PEMBAHASAN}

Pembuatan pemodelan transfer panas dan massa pada kamar pengering dimulai dengan menyusun persamaan matematisnya kemudian diselesaikan menggunakan metode numerik. Pada pemodelan ini digunakan batasan masalah sebagai berikut:

1. Ruang pengering yang digunakan adalah tipe rak.

2. Rak diberi isolasi sehingga dapat diasumsikantidakada perpindahan panas antara rak dengan bahan yang dikeringkan.

3. Aliran udara panas yang dilewatkan pada rak adalah sistem paralel sehingga rak memperoleh udara kering, dengan ketentuan menembus padatan atau material yang berbentuk bola.

4. Transfer panas yang terjadi pada sistem adalah konduksi dan konveksi. 
5. Transfer massa yang memenuhi keadaan adalah difusi dan penguapan.

6. Bahan yang akan dikeringkan berbentuk butiran yang ditumpuk dengan ketebalan tertentu.

7. Suhu dan kadar air butiran pada keadaan awal diasumsikan homogen (tidak ada gradien suhu dan kadar air dalam butiran).

8. Parameter input yang berasal dari pompa kalor berupa suhu udara, laju aliran udara, dan kelembaban udara.

9. Sifat-sifat fisis bahan yang dikeringkan meliputi massa jenis, konduktivitas termal dan kapasitas panas diasumsikan tetap selama proses pengeringan.

10. Laju alir udara, kelembaban dan suhu udara masuk diasumsikan tetap selama proses pengeringan berlangsung.

Padatan yang akan dikeringkan berupa butiran yang ditumpuk dengan ketinggian tertentu sebagaimana Gambar 1.

\section{Aliran udara}

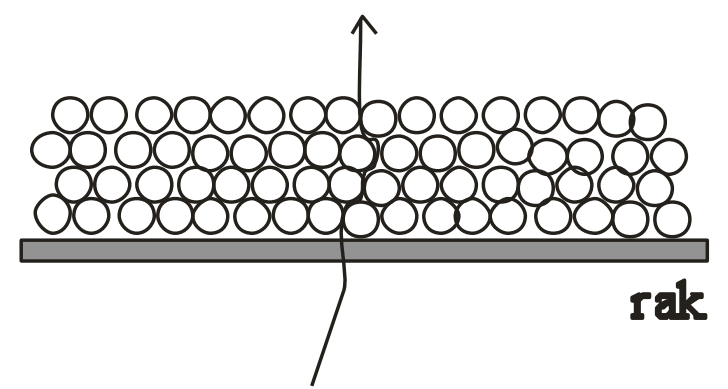

Gambar 1. Peletakan butiran yang akan dikeringkan

Dengan peletakan seperti ini padatan tersebut dapat diasumsikan sebagai benda porous, sehingga dapat dimodelkan seperti pada Gambar 2.

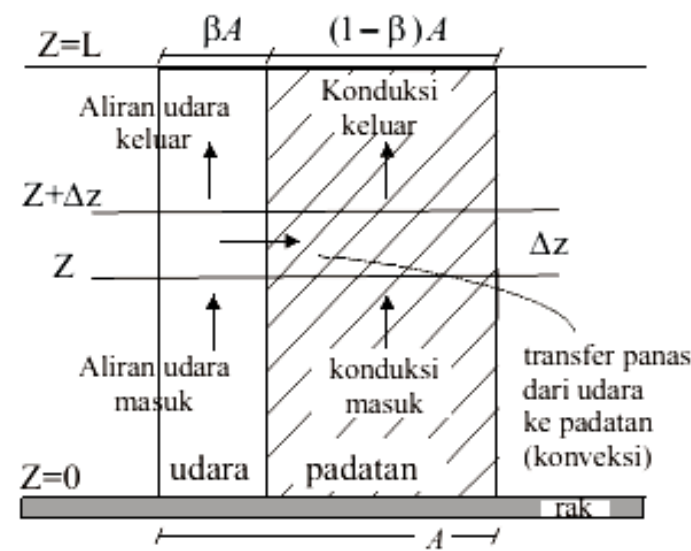

(a)

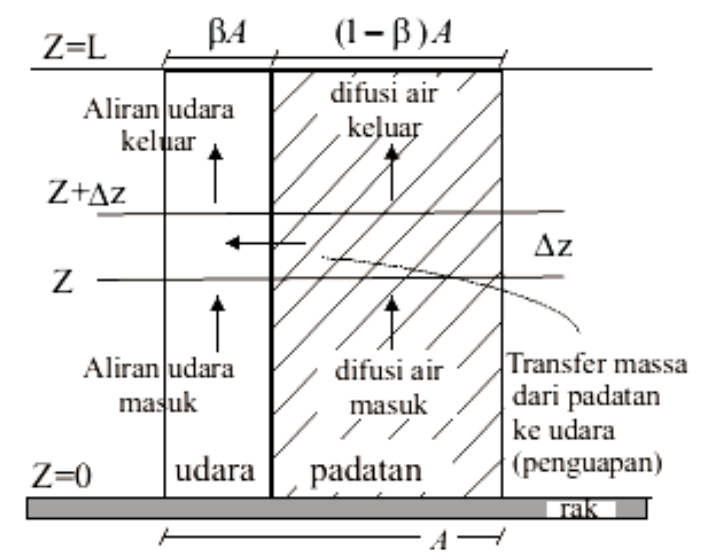

(b)

Gambar 2. Pemodelan benda porous. (a)transfer panas, (b)transfer massa

Dalam satu rak sistem dibagi menjadi dua, yaitu padatan dan udara. Volume udara dalam satu rak adalah hasil perkalian luas penampang rak dengan porositas $(\beta)$ bahan, sedangkan volume padatan adalah hasil perkalian luas penampang rak terhadap $1-\beta$. Selanjutnya akan dicari persamaan transfer panas dan massa pada padatan dan udara.

Berdasarkan Gambar 2, dapat diketahui bahwa proses transfer panas terjadi pada dua fase yaitu padatan dan udara. Neraca kesetimbangan energipada padatan dapat dituliskan sebagai berikut:

(konduksi masuk) - (konduksi keluar) (transfer panas dari udara ke padatan $)=$ akumulasi. 


$$
\begin{aligned}
& -\left.(1-\beta) A k \frac{d T}{d z}\right|_{z}-\left(-\left.(1-\beta) A k \frac{d T}{d z}\right|_{z+\Delta z}\right) \\
& -\left(h A_{s p}\left(T_{u}-T_{s}\right)\right)=\frac{d}{d t} \Delta V(1-\beta) \rho_{s}\left(c_{p, s}+X_{s} c_{p, w l}\right) T_{s}
\end{aligned}
$$

Setelah disederhanakan dapat ditulis ulang menjadi

$$
\frac{\partial^{2} T}{\partial z^{2}}-\frac{h a}{(1-\beta)}\left(T_{u}-T_{s}\right)=\frac{1}{\alpha_{\text {eff }}} \frac{\partial T_{s}}{\partial t}
$$

dengan syarat batas di $\mathrm{Z}=0$

$$
\frac{\partial T}{\partial z}=\frac{h}{k}\left(T_{u_{i n}}-T_{s}\right)
$$

syarat batas di $\mathrm{Z}=\mathrm{L}$

$$
-\frac{\partial T}{\partial z}=\frac{h}{k}\left(T_{u_{i n}}-T_{s}\right)
$$

dan

$$
\alpha_{\mathrm{eff}}=\frac{k}{\rho_{s}\left(c_{p, s}+X_{s} c_{p, w l}\right)} .
$$

Pada keadaan awalnya $(\mathrm{t}=0) T_{u}=T_{u 0}$.

Neraca kesetimbangan energi pada udara dapat dituliskan sebagai berikut:

(aliran udara masuk) - (aliran udara keluar) - (konveksi dari udara ke padatan) = akumulasi

$\left.{ }_{n} \underset{u}{\mathrm{x}}\left(c_{p, u}+X_{u} c_{p, w u}\right)\left(T-T_{0}\right)\right|_{z}-$

$\left.\operatorname{mox}_{u}\left(c_{p, u}+X_{u} c_{p, w u}\right)\left(T-T_{0}\right)\right|_{z+\Delta z}-h A_{s p}\left(T_{u}-T_{s}\right)$

$=\frac{d}{d t} \Delta V \beta \rho_{u}\left(c_{p, u}+X_{u} c_{p, w u}\right) T_{u}$

Setelah disederhanakan menjadi

$-\frac{v}{\beta} \frac{\partial T}{\partial z}-\frac{h a}{\beta \rho_{u}\left(c_{p, u}+X_{u} c_{p, w u}\right)}\left(T_{u}-T_{s}\right)=\frac{\partial T_{u}}{\partial t}$

dengan syarat batas di $\mathrm{z}=0$ adalah $T_{u}=T_{u_{i n}}$,sedangkan keadaan awalnya (t=0) adalah $T_{u}=T_{u_{\text {in }}}$

Neraca kesetimbangan massapada padatan dapat dituliskan sebagai berikut: difusi air masuk - difusi air keluar transfer massa air padatan ke udara = akumulasi

$$
\begin{aligned}
& \left.\left(-(1-\beta) A D \frac{\Delta C_{s}}{\Delta z}\right)\right|_{z}-\left.\left(-(1-\beta) A D \frac{\Delta C_{s}}{\Delta z}\right)\right|_{z+\Delta z} \\
& +k y A_{s p}\left(C_{s}-K C_{u}\right)=\frac{\partial}{\partial t} \Delta V(1-\beta) C_{c}
\end{aligned}
$$

Setelah disederhanakan menjadi

$$
\begin{aligned}
& D \frac{\partial^{2}}{\partial z^{2}} X_{s}-\frac{k y a}{\rho_{s}(1-\beta)} \rho_{s}\left(X_{s}-K \frac{\rho_{u}}{\rho_{s}} X_{u}\right) \\
& =\frac{\partial}{\partial t} X_{s}
\end{aligned}
$$

dengan syarat batas di $\mathrm{z}=0$ adalah

$$
\frac{\partial X_{s}}{\partial z}=\frac{k y}{D}\left(X_{s}-K \frac{\rho_{u}}{\rho_{s}} X_{u_{\text {in }}}\right)
$$

sedangkan di $\mathrm{z}=\mathrm{L}$ adalah

$$
-\frac{\partial X_{s}}{\partial z}=\frac{k y}{D}\left(X_{s}-K \frac{\rho_{u}}{\rho_{s}} X_{u_{i n}}\right)
$$

dan pada keadaan awalnya $(\mathrm{t}=0)$

$$
X_{s}=X_{s 0}
$$

Neraca kesetimbangan massapada udara dapat dituliskan sebagai berikut :

aliran udara masuk - aliran udara keluar

+ penguapan dari padatan ke udara

= akumulasi

$$
\begin{aligned}
& \left.\prod_{u} X_{u}\right|_{z}-\left.n \&_{u} X_{u}\right|_{z+\Delta z}+k y A_{s p} \rho_{s}\left(X_{s}-K \frac{\rho_{u}}{\rho_{s}} X_{u}\right) \\
& =\beta \frac{\partial}{\partial t} \Delta V \rho_{u} X_{u}
\end{aligned}
$$

Setelah disederhanakan menjadi

$$
\begin{aligned}
& -\frac{v}{\beta} \frac{\partial}{\partial z} X_{u}+\frac{k y a}{\beta}\left(\frac{\rho_{s}}{\rho_{u}} X_{s}-K X_{u}\right) \\
& =\frac{\partial}{\partial t} X_{u}
\end{aligned}
$$

dengan syarat batas di $\mathrm{z}=0$ adalah

$$
X_{u}=X_{u_{i n}}
$$

Demikian juga dengan keadaan awalnya $(\mathrm{t}=0)$ adalah $X_{u}=X_{u_{i n}}$

Penyelesaian secara numerik memungkinkan komputer untuk melakukan perhitungan. Dalam penelitian ini metode numerik yang digunakan adalah metode beda tengah dengan penyelesaian secara eksplisit.

Dengan menggunakan Metode beda tengah persamaan 1 menjadi: 


$$
\begin{aligned}
& \frac{\left[T_{s_{j+1, t}}-2 T_{s_{j, t}}+T_{s_{j-1, t}}\right]}{\Delta z^{2}}+\frac{h a}{k(1-\beta)}\left[T_{u_{j, t}}-T_{s_{j, t}}\right] \\
& =\frac{1}{\alpha_{e f f}}\left[\frac{T_{s_{j, t+\Delta t}}-T_{s_{j, t}}}{\Delta t}\right]
\end{aligned}
$$

Setelah persamaan 5 disederhanakan disederhanakan menjadi

$$
\begin{aligned}
& T_{s_{j, t+\Delta t}}=\left(\frac{\Delta t}{\Delta z^{2}} \alpha_{e f f}\right) T_{s_{j+1, t}}+ \\
& \left(1-\frac{2 \Delta t \alpha_{e f f}}{\Delta z^{2}}-\frac{h a \Delta t \alpha_{e f f}}{k(1-\beta)}\right) T_{s_{j, t}}+ \\
& \left(\frac{\Delta t \alpha_{e f f}}{\Delta z^{2}}\right) T_{s_{j-1, t}}+\left(\frac{h a \Delta t \alpha_{e f f}}{k(1-\beta)}\right) T_{u_{j, t}}
\end{aligned}
$$

Bentuk syarat batas di $\mathrm{Z}=0$ dan $\mathrm{Z}=\mathrm{L}$ masing masing menjadi

$$
T_{s_{j-1, t}}=T_{s_{j+1, t}}-\frac{h}{k}(2 \Delta z) T_{u_{i n j, t}}+\frac{h}{k}(2 \Delta z) T_{s j, t}
$$

dan

$$
T_{s_{j+1, t}}=T_{s_{j-1, t}}+\frac{h}{k}(2 \Delta z) T_{s j, t}-\frac{h}{k}(2 \Delta z) T_{u_{j, t}}
$$

Lalu persamaan 7 dan 8 disubstitusikan ke persamaan 6 sehingga menjadi

$$
\begin{aligned}
& T_{s_{j, t+\Delta t}}=\left(\begin{array}{l}
1+\frac{h}{k} \frac{2 \Delta t \alpha_{e f f}}{\Delta z}-\frac{2 \Delta t \alpha_{e f f}}{\Delta z^{2}}- \\
\frac{h a \Delta t \alpha_{e f f}}{k(1-\beta)}
\end{array}\right) T_{s_{j, t}} \\
& +\left(\frac{2 \Delta t \alpha_{e f f}}{\Delta z^{2}}\right) T_{s_{j-1, t}}+\left(\frac{h a \Delta t \alpha_{e f f}}{k(1-\beta)}\right) T_{u_{j, t}} \\
& -\frac{h}{k} \frac{2 \Delta t \alpha_{e f f}}{\Delta z} T_{u_{\text {out } j, t}}
\end{aligned}
$$

Dengan cara yang sama diperoleh persamaan transfer panas pada udara,

$$
\begin{aligned}
& T_{u_{j, t+\Delta t}}=-\frac{v \Delta t}{\beta 2 \Delta z} T_{u_{j+1, t}}+ \\
& \left(1-\frac{h a \Delta t}{\beta \rho_{u}\left(C p_{u}+X_{u} C p_{w u}\right)}\right) T_{u_{j, t}} \\
& +\frac{v \Delta t}{\beta 2 \Delta z} T_{u_{j-1, t}}+\left(\frac{h a \Delta t}{\beta \rho_{u}\left(C p_{u}+X_{u} C p_{w u}\right)}\right) T_{s_{j, t}}
\end{aligned}
$$

Persamaan transfer massa pada padatan,

$$
\begin{aligned}
& X_{s_{j,+\Delta t}}=\left(1-\frac{2 D \Delta t}{\Delta z^{2}}-\frac{k y a \Delta t}{(1-\beta)}-\frac{2 \Delta t k y}{\Delta z}\right) X_{s_{j, t}} \\
& +\left(\frac{\Delta t k y a}{(1-\beta)} \frac{K \rho_{u}}{\rho_{s}}\right) X_{u_{j, t}}+\left(\frac{2 \Delta t D}{\Delta z^{2}}\right) X_{s_{j-1, t}} \\
& +\left(\frac{2 \Delta t k y}{\Delta z} \frac{K \rho_{u}}{\rho_{s}}\right) X_{u_{i j}}
\end{aligned}
$$

dan persamaan transfer massa pada udara.

$$
\begin{aligned}
& X_{u_{j, t+\Delta t}}=-\left(\frac{v \Delta t}{\beta(2 \Delta z)}\right) X_{u_{j+1, t}} \\
& +\left(1-\frac{\Delta t k y a K}{\beta}\right) X_{u_{j, t}}+\left(\frac{v \Delta t}{\beta(2 \Delta z)}\right) X_{u_{j-1, t}} \\
& +\frac{\Delta t k y a}{\beta} \frac{\rho_{s}}{\rho_{u}} X_{s_{j, t}}
\end{aligned}
$$

Langkah terakhir adalah menentukan syarat kesetabilan. Penyelesaian secara eksplisit akan relevan jika syarat kesetabilannya dipenuhi. Syarat kesetabilan persamaan numerik dihitung dengan mengkondisikan semua koefisiennya bernilai positif. Dari persamaan numerik yang didapat, koefisien-koefisien yang memungkinkan bernilai negatif adalah sebagai berikut:

1. $\Delta t \leq \frac{1}{\alpha_{e f f}\left(\frac{2}{\Delta z^{2}}-\frac{h a}{k(1-\beta)}\right)}$

2. $\Delta t \leq \frac{1}{\alpha_{e f f}\left(\frac{2}{\Delta z^{2}}+\frac{h a}{k(1-\beta)}-\frac{h}{k} \frac{2}{\Delta z}\right)}$

3. $\Delta t \leq \frac{\beta \rho_{u}\left(C p_{u}+X_{u} C p_{w u}\right)}{h a \Delta t}$

4. $\Delta t \leq \frac{1}{\left(\frac{2 D}{\Delta z^{2}}-\frac{k y a}{(1-\beta)}\right)}$

5. $\Delta t \leq \frac{1}{\left(\frac{2 D}{\Delta z^{2}}+\frac{k y a}{(1-\beta)}+\frac{2 k y}{\Delta z}\right)}$

6. $\Delta t \leq \frac{\beta}{\text { ky } a K}$

Agar stabil, dari ke enam syarat kestabilan tersebut diambil $\Delta \mathrm{t}$ yang paling 
kecil. Semakin kecil nilai $\Delta \mathrm{t}$ yang digunakan, maka hasil perhitungannya akan semakin teliti.

Keterangan simbol:

$$
\begin{aligned}
& \beta=\text { porositas } \\
& A \quad=\text { luas area transfer panas (m) } \\
& A_{s p} \quad=\text { luas area konveksi padatan (m) } \\
& k=\text { konduktivitas termal }(\mathrm{W} / \mathrm{mK}) \\
& h=\text { koefisien } \operatorname{konveksi}\left(\mathrm{W} / \mathrm{m}^{2} \mathrm{~K}\right) \\
& V \quad=\text { volume transfer panas }\left(\mathrm{m}^{3}\right) \\
& \rho_{s} \quad=\text { massa jenis padatan }\left(\mathrm{kg} / \mathrm{m}^{3}\right) \\
& \rho_{u} \quad=\text { massa jenis udara }\left(\mathrm{kg} / \mathrm{m}^{3}\right) \\
& c_{p, s} \quad=\text { kapasitas panas spesifik padatan } \\
& (\mathrm{J} / \mathrm{kg} . \mathrm{K}) \\
& c_{p, w l}=\text { kapasitas panas spesifik air di } \\
& \text { padatan (J/kg.K) } \\
& c_{p, u}=\text { kapasitas panas udara }(\mathrm{J} / \mathrm{kg} . \mathrm{K}) \\
& c_{p, w u}=\text { kapasitas panas air di udara } \\
& \text { (J/kg.K) } \\
& T_{u} \quad=\text { temperatur udara }(\mathrm{K}) \\
& T_{s} \quad=\text { temperatur padatan }(\mathrm{K}) \\
& T_{0} \quad=\text { temperatur mula-mula }(\mathrm{K}) \\
& D=\text { difusifitas massa }\left(\mathrm{m}^{2} / \mathrm{s}\right) \\
& C_{s} \quad=\text { konsentrasi air di padatan } \\
& \left(\mathrm{kmol} / \mathrm{m}^{3}\right) \\
& \text { ky = konstanta konveksi padatan } \\
& \text { udara }(\mathrm{m} / \mathrm{s}) \\
& K=\text { konstanta kesetimbangan } \\
& \dot{m}_{u}=\text { laju alir massa udara }(\mathrm{kg} / \mathrm{s}) \\
& X_{u} \quad=\text { kadar air di udara }(\mathrm{kg} \text { air } / \mathrm{kg} \\
& \text { udara kering) } \\
& X_{s} \quad=\text { kadar air padatan }(\mathrm{kg} \text { air } / \mathrm{kg} \\
& \text { padatan kering) }
\end{aligned}
$$

\section{SIMPULAN DAN SARAN}

Solusi Numerik perpindahan panas dan massa pada proses pengeringan bijibijian telah berhasil di susun. Untuk menerapkan persamaan ini perlu memperhatikan syarat kesetabilan. Hasil perhitungan akan lebih presisi jika selang waktu yang digunakan semakin kecil.

\section{UCAPAN TERIMA KASIH}

Ucapan terima kasih penulis sampaikan pada kepala Laboratorium pengembangan pendidikan fisikaUPGRIS, LPPM UPGRIS, dan semua pihak yang telah membantu terlaksananya penelitian ini.

\section{DAFTAR PUSTAKA}

Agustina, R., Syah, H., \& Moulana, R. (2016). Karakteristik Pengeringan Biji Kopi dengan Pengering Tipe Bak dengan Sumber Panas Tungku Sekam Kopi dan Kolektor Surya. Jurnal Ilmiah Teknologi Pertanian Agrotechno, 1(1), 20-27.

Putra, G. M. D., Setiawati, D. A., \& Hartini, S. (2016). Kajian Pindah Panas Tungku Biomassa Dan Heat Exchanger PadaAlat Pengering Hybrid Berbahan Bakar Limbah Biomass. Rekayasa Pertanian Dan Biosistem (JRPB), 3(2), 159-162.

Rahayuningtyas, A., \& Afifah, N. (2016). Rancang Bangun, Uji Performa dan Analisa Biaya Pengeringan Irisan Singkong Menggunakan Pengering Inframerah (Design, Construction, Performance Evaluation and Cost Analysis of Cassava Chips Using Infrared Dryer). JURNAL PANGAN, 25(1), 33-42.

Romdhana, H., Lambert, C., Goujot, D., \& Courtois, F. (2016). Model reduction technique for faster simulation of drying of spherical solid foods. Journal of Food Engineering, 170, 125-135.

Silva, W. P. D., Rodrigues, A. F., Silva, C. M. D. E., \& Gomes, J. P. (2016). Numerical Approach to Describe Continuous and Intermittent Drying Including the Tempering Period: Kinetics and Spatial Distribution of Moisture. Drying Technology, (justaccepted).

Zdanski, P. S. B., \& Silva, D. (2016). Numerical Simulation of The Incompressible Turbulent Flow of a 
Binary Mixture Of Air-Water Vapor:

Applications In Drying Process.

Brazilian Journal of Chemical

Engineering, 33(2), 287-296.

Zheng, S., Song, K., Zhao, J., \& Dong, C.

(2016). Inverse Estimation of

Effective Moisture Diffusivity in

Lumber during Drying Using

Genetic Algorithms. BioResources, 11(4), 8226-8238. 